\title{
A Serious Puzzle Game to Enhance Adherence to Antirheumatic Drugs in Patients With Rheumatoid Arthritis: Systematic Development Using Intervention Mapping
}

Bart PH Pouls ${ }^{1,2}$, PharmD; Charlotte L Bekker ${ }^{2}, \mathrm{PhD}$; Sandra van Dulmen ${ }^{3,4}$, Prof Dr; Johanna E Vriezekolk ${ }^{1}, \mathrm{PhD}$; Bart JF van den Bemt ${ }^{1,2}$, PharmD, Prof Dr

\footnotetext{
${ }^{1}$ Department of Rheumatology Research, Sint Maartenskliniek, Nijmegen, Netherlands

${ }^{2}$ Department of Pharmacy, Radboud Institute for Health Sciences, Radboud University Medical Centre, Nijmegen, Netherlands

${ }^{3}$ Department of Primary and Community Care, Radboud Institute for Health Sciences, Radboud University Medical Centre, Nijmegen, Netherlands

${ }^{4}$ Netherlands Institute for Health Services Research, Utrecht, Netherlands
}

\section{Corresponding Author:}

Bart PH Pouls, PharmD

Department of Rheumatology Research

Sint Maartenskliniek

Hengstdal 3

Nijmegen, 6574NA

Netherlands

Phone: 31612502678

Email: b.pouls@maartenskliniek.nl

\section{Abstract}

Background: Patients' implicit attitudes toward medication need and concerns may influence their adherence. Targeting these implicit attitudes by combining game-entertainment with medication-related triggers might improve medication adherence in patients with rheumatoid arthritis (RA).

Objective: The aim of this study was to describe the systematic development of a serious game to enhance adherence to antirheumatic drugs by using intervention mapping.

Methods: A serious game was developed using the intervention mapping framework guided by a multidisciplinary expert group, which proceeded along 6 steps: (1) exploring the problem by assessing the relationship between medication adherence and implicit attitudes, (2) defining change objectives, (3) selecting evidence-based behavior change techniques that focused on adjusting implicit attitudes, (4) designing the intervention, (5) guaranteeing implementation by focusing on intrinsic motivation, and (6) planning a scientific evaluation.

Results: Based on the problem assessment and guided by the Dual-Attitude Model, implicit negative and illness-related attitudes of patients with RA were defined as the main target for the intervention. Consequently, the change objective was "after the intervention, participants have a more positive attitude toward antirheumatic drugs." Attention bias modification, evaluative conditioning, and goal priming were the techniques chosen to implicitly target medication needs. These techniques were redesigned into medication-related triggers and built in the serious puzzle game. Thirty-seven patients with RA tested the game at several stages. Intrinsic motivation was led by the self-determination theory and addressed the 3 needs, that is, competence, autonomy, and relatedness. The intervention will be evaluated in a randomized clinical trial that assesses the effect of playing the serious game on antirheumatic drug adherence.

Conclusions: We systematically developed a serious game app to enhance adherence to antirheumatic drugs among patients with RA by using the intervention mapping framework. This paper could serve as a guideline for other health care providers when developing similar interventions.

(JMIR Serious Games 2022;10(1):e31570) doi: $\underline{10.2196 / 31570}$

\section{KEYWORDS}

medication adherence; serious game; eHealth; rheumatoid arthritis; intervention mapping; intervention development 


\section{Introduction}

Rheumatoid arthritis (RA) is an autoimmune disease characterized by symmetric chronic polyarthritis which, if untreated, leads to pain, joint damage, and decreased quality of life $[1,2]$. The cornerstone of RA treatment is the use of antirheumatic drugs (disease-modifying antirheumatic drugs [DMARDs]), which reduce disease activity, radiological progression, and increases patient's functioning [3,4]. These benefits are not achieved when patients are nonadherent to their long-term therapy [5,6]. It is estimated that around one-third of the patients with RA are nonadherent to antirheumatic drug therapy [7-9]. As such, achieving medication adherence remains a major challenge for a substantial proportion of patients with RA. Understanding medication nonadherence and its causes helps to identify targets for the development of adherence interventions. Practical barriers (eg, forgetfulness, costs) and patient's attitudes toward medication (eg, balance between necessity and concerns) are associated with medication nonadherence $[10,11]$. Thus, these factors have frequently been the main target of interventions aiming to improve adherence [12]. Unfortunately, adherence interventions have been only partly effective [13-16].

Part of this ineffectiveness might be because the medication-taking behavior is not yet fully elucidated. Behavioral intentions such as taking medication are driven by a person's explicit (conscious) and implicit (unconscious) attitudes [17]. These attitudes do not necessarily have to be congruent. Someone might explicitly say that medication helps alleviate symptoms but implicitly regard medication as chemical rubbish [17,18]. Habitual behavior, like medication-taking behavior, happens mainly on an unconscious level and is more likely to be guided by implicit attitudes [19]. Therefore, targeting implicit attitudes might be an effective strategy to improve medication adherence.

Implicit attitudes are targeted by reinterpretation training, that is, exercising the brain to interpret a stimulus differently [20]. This can, for instance, be achieved by performing tasks that lead to pairing of a medication stimulus with another positive stimulus [21]. Such a reinterpretation training needs rigorous and repetitive exercising to be successful or, in other words, a multidose intervention is required. eHealth can be a suitable mode of delivery for a multidose intervention as it is easily accessible and allows patients to perform these tasks at a convenient time and place. Retention of a multidose intervention is best achieved when participants are intrinsically motivated to prevent dropout prior to the effect of the intervention being reached.

Motivation can be maintained by formatting the intervention as a serious game $[22,23]$. Serious games are games that intend to entertain and achieve at least one additional goal [22]. In order to motivate patients to play the serious game, the self-determination theory may be used to guide serious game development. According to this theory, intrinsic motivation is most likely to occur when 3 needs are satisfied: competence, autonomy, and relatedness [24,25]. A serious game can satisfy these 3 needs, creating intrinsically motivated players who will adhere to a multidose intervention. Thus, serious games can positively influence behavior [26] even by targeting implicit attitudes [27].

Taken together, this paper describes the systematic development of a serious game by using the intervention mapping framework [28]. This serious game should provide entertainment as well as positively influence medication adherence by targeting implicit attitudes.

\section{Methods}

\section{Development Process}

Intervention mapping was used to systematically develop the intervention [29]. Intervention mapping considers and applies theory and empirical evidence to maximize the effectiveness and usability of the intervention, covers the complete range from problem identification to scientific evaluation, and ensures that the intervention is compatible with the target population [29]. A complex problem such as a medication-taking behavior demands a multidisciplinary approach. Therefore, the intervention mapping process was guided by meetings of an expert group consisting of a pharmacist, rheumatologist, rheumatology nurse, psychologist, innovation manager, representative of the pharmaceutical industry, and a game developer named Games for Health.

\section{Intervention Mapping Framework}

The intervention mapping framework comprises 6 steps, where each step leads to a product that guides the subsequent step. See Table 1 for an overview of intervention mapping steps with associated tasks and intermediate development products. The goal of the first step is to assess the health problem. The main task in this step is to identify the determinants for the at-risk population of the problematic behavior (nonadherence). Step 2 builds on the previous step by using the identified determinants to formulate the change objectives. The change objectives specify who and what will change as a result of the intervention. In step 3, theory-informed methods and practical strategies are searched for that are most likely to accomplish the formulated change objectives. During step 4, the intervention is produced based on the outcomes of the previous steps and refined after pilot testing. The goal of step 5 is to increase program adoption, implementation, and maintenance by creating an implementation plan. Finally, in step 6 , the effect of the intervention is evaluated to ensure that the desired behavioral outcome is achieved. 
Table 1. Intervention mapping steps with associated tasks and applied methodology.

\begin{tabular}{|c|c|c|}
\hline jing steps & apping tasks & Methods \\
\hline $\begin{array}{l}\text { Step 1: Logic } \\
\text { problem }\end{array}$ & $\begin{array}{l}\text { Describe the context for the intervention } \\
\text { Identify determinants for the at-risk population of the } \\
\text { problem }\end{array}$ & $\begin{array}{l}\text { PubMed literature search on determinants of nonadherence } \\
(2010-2015) \\
\text { Explorative study in } 52 \text { patients on relation between attitudes } \\
\text { and medication adherence }\end{array}$ \\
\hline $\begin{array}{l}\text { Step 2: Program outcomes } \\
\text { and objectives }\end{array}$ & $\begin{array}{l}\text { State expected outcomes for behavior } \\
\text { Specify performance objectives for behavioral outcomes } \\
\text { Select determinants for behavioral outcomes } \\
\text { Create a logic model of change }\end{array}$ & $\begin{array}{l}\text { Multiple expert group discussions (both face-to-face and } \\
\text { electronic) }\end{array}$ \\
\hline Step 3: Program design & $\begin{array}{l}\text { Generate program themes, components, scope, and se- } \\
\text { quence } \\
\text { Choose theory- and evidence-based change methods } \\
\text { Select or design practical apps to deliver change methods }\end{array}$ & $\begin{array}{l}\text { Literature search and expert opinion on behavior change tech- } \\
\text { niques } \\
\text { Multiple expert group discussions } \\
\text { Iterative game development }\end{array}$ \\
\hline $\begin{array}{l}\text { Step 4: Program } \\
\text { production }\end{array}$ & $\begin{array}{l}\text { Refine program structure and organization } \\
\text { Prepare plans for program materials } \\
\text { Draft messages, materials, and protocols } \\
\text { Pretest, refine, and produce materials }\end{array}$ & $\begin{array}{l}\text { Iterative game development } \\
\text { Stage } 1 \text { user testing: } 54 \text { disease-modifying antirheumatic drug } \\
\text { users played at home in } 2 \text { rounds for } 2 \text { weeks } \\
\text { Stage } 2 \text { user testing: } 8 \text { disease-modifying antirheumatic drug } \\
\text { users performed a live walk-through }\end{array}$ \\
\hline $\begin{array}{l}\text { Step 5: Program } \\
\text { implementation plan }\end{array}$ & $\begin{array}{l}\text { State outcomes and performance objectives for program } \\
\text { use } \\
\text { Construct matrices of change objectives for program } \\
\text { use }\end{array}$ & Iterative game development guided by self-determination theory \\
\hline Step 6: Evaluation plan & $\begin{array}{l}\text { Write effect and process evaluation questions } \\
\text { Develop indicators and measures for assessment } \\
\text { Specify the evaluation design }\end{array}$ & $\begin{array}{l}\text { Develop a randomized clinical trial study protocol to examine } \\
\text { effectiveness on medication adherence of antirheumatic drugs } \\
\text { (GAMER [Gaming for Adherence to Medication using E-health } \\
\text { in Rheumatoid arthritis patients] study) }\end{array}$ \\
\hline
\end{tabular}

\section{Logic Model of the Problem}

As the first step, the context of the intervention (population and setting) is described. Next, 2 methods were used to identify the determinants for patients with rheumatic disease being at-risk for nonadherence: (1) a literature search and (2) an explorative study on the implicit and explicit determinants toward antirheumatic drug use performed by research team members [30]. The literature search was performed in PubMed in 2015, and it focused on recent (2010-2015) studies, including systematic reviews, using the MeSH terms medication adherence and rheumatic diseases coupled with free text term determinant. Both primary studies and systematic reviews were included. All determinants mentioned in the selected studies and their association with medication adherence were collected and split into nonmodifiable and modifiable factors. Nonmodifiable factors aid in identifying the target population, whereas modifiable factors aid in identifying target behavior. Habitual behavior such as medication-taking behavior is likely to be guided by implicit attitudes as well as explicit attitudes [19]. However, it is unclear how explicit and implicit attitudes relate to medication adherence. Therefore, this was explored by research team members in a sample of patients with RA and published elsewhere [30]. In short, the sample consisted of 52 patients on oral methotrexate therapy at Sint Maartenskliniek, a Dutch tertiary rheumatology clinic. Patients were approached when collecting their medication refill, and assessment took place immediately after providing informed consent. Patients performed a computerized task (Single Category Implicit Association Test) to measure the implicit measures of medication attitudes and associations, which is a well-established and valid measure of implicit associations [31]. Additionally, they completed a questionnaire on demographics and questionnaires on explicit attitudes and associations (Beliefs about Medication Questionnaire [BMQ] [32-35]) and medication adherence (Compliance Questionnaire on Rheumatology [CQR] [36-38]), both proven valid and reliable in patients with RA. Clinical outcomes (erythrocyte sedimentation rate and C-reactive protein) were obtained from patients' medical files. Because of the explorative character of this study, Pearson correlations were used to examine the relationship between patients' explicit and implicit attitudes, associations, beliefs, adherence, clinical outcomes, and demographics.

\section{Program Outcomes and Objectives}

The behavioral outcome of the intervention is to become adherent and maintain medication adherence of antirheumatic drugs. As the patient is the one who has the main influence on the medication-taking behavior, we only defined change objectives at the patient level. Thus, there are no change objectives at the interpersonal, organizational, communal, or societal level. The change objective of the intervention was guided by the outcomes of step 1 and established through multiple (electronic) discussions of the expert group through an organic iterative process.

\section{Program Design}

The fundament of the behavioral change for our intervention was the Dual-Attitude model. The Dual-Attitude model postulates that implicit and explicit attitudes coexist and do not 
necessarily have to be congruent $[17,30]$. When dual attitudes exist, the implicit attitude is activated automatically, whereas the explicit one requires more capacity and motivation to retrieve from memory. As such, habitual behavior such as medication-taking behavior is more likely to be guided by implicit attitudes [19]. Implicit attitudes can be targeted by a behavior change technique called bias modification [20]. Google Scholar and PubMed were narratively searched for suitable behavior change techniques. The search terms consisted of free text words, that is, behavior change technique, bias modification, and health. To narrow the search results, the terms review and overview were added to the search strategy. The behavior change techniques shown to effectively address health behaviors were selected and presented to the game developer for applicability. Next, the game type was carefully chosen to suit the context (target population and setting) of the intervention from step 1.

\section{Program Production}

The serious game was developed using an iterative design process. Based on the theory of the previous steps, the expert group prepared the outline of the intervention components in multiple sessions. Games for Health used their expertise to create the components within the technical possibilities and merged them to form the game. The game was tested by patients and the feedback used to adapt the game after which this process was repeated. Thus, the final product is a practical interpretation of the theory. The test panel members were representative of the target group and were recruited from Sint Maartenskliniek, Nijmegen, The Netherlands. They were patients aged 16 years or older who used antirheumatic drugs. Ethical approval for user testing was asked for and waived by the local medical research ethics committee of Arnhem-Nijmegen under code 2017-3355. A random sample of 500 patients using DMARDs received an invitation with informed consent enclosed through mail. Additionally, participants needed to possess a tablet and be proficient in the Dutch language.

Stage 1 consisted of 2 rounds of 2 weeks of user testing at home after which data on acceptability were collected. Acceptability was determined using the Technology Acceptance Model as underpinning, which is a well-established model for usability evaluation of eHealth [39-41]. This model postulates that ease of using a technology influences the perceived usefulness and the attitude toward using and together form the behavioral intention to use a technology, which leads to actual use. Ease of use was measured using the System Usability Scale questionnaire taken directly from the Technology Acceptance Model $[39,42,43]$. The perceived usefulness of a game was operationalized as enjoyment and assessed using the GameFlow questionnaire, which has been successfully applied to distinguish between the high-rated and low-rated games and identify why one succeeded and the other failed $[44,45]$. Attitude toward using was assessed using 4 questions of the user version of the Mobile App Rating Scale (uMARS), which is a simpler end-user version of the validated MARS [46,47]. The questions of the uMARS that captured the overall feeling of the app and its potential use were selected by authors BPHP and BJFvdB until consensus was reached. All other questions were omitted, as they related to other aspects of mobile apps and even overlapped with ease of use and usefulness. Actual use was collected using Google Analytics and determined to be time played and number of sessions. In addition, participants were asked for their overall experience and suggestions for improvement (open-ended questions) to inform the game developers.

Stage 2 was a live walk-through where patients performed tasks within the serious game environment under supervision. A team of game developers from Games for Health and author BPHP observed the participants and took notes. Participants were recruited from players in stage 1 (experienced users) and from the patient representatives of Sint Maartenskliniek (new users). Suggestions for improvement were collected with the aim of improving gameplay and increasing retention.

\section{Program Implementation Plan}

Intrinsic motivation is key to ensure adoption and implementation of a serious game. The self-determination theory posits that motivation is a continuum between extrinsic motivation (ie, external factors such as rewards or grades) and intrinsic motivation (ie, internal factors such as interest, curiosity, or care). Intrinsic motivation can be reliably enhanced by supporting the satisfaction of 3 psychological needs: competence, autonomy, and relatedness $[24,25,48]$. Competence denotes the experience of mastery. It becomes satisfied when capably engaging in activities and experiencing opportunities for using and extending skills. Autonomy denotes the experience of willpower and willingness without external pressure. Relatedness denotes the experience of bonding and care and is satisfied by connecting to others. In the Results section, we have described how our serious game addresses these needs.

\section{Evaluation Plan}

To assess whether the developed intervention positively affects antirheumatic drug adherence, a research proposal was drafted for a multicenter randomized controlled trial: the GAMER (Gaming for Adherence to Medication using E-health in Rheumatoid arthritis patients) study.

\section{Results}

\section{Logic Model of the Problem}

The intervention is set within the context of RA. RA mainly affects people older than 50 years and is more common among women [1]. Because most antirheumatic drugs are used at home, our adherence-enhancing intervention should be utilized in the home setting. The literature search on determinants of nonadherence resulted in 73 publications, of which 12 detailed on determinants of medication adherence in rheumatic diseases [7,10,11,49-57]. There were no nonmodifiable patient characteristics that indisputably predicted medication nonadherence. Therefore, we decided that our intervention should be aimed at all patients with RA. The modifiable determinants that remained were psychosocial and therapy-related factors. As our intervention should not interfere with RA treatment, we focused on psychosocial factors. Supportive evidence was found for the following modifiable psychosocial factors influencing medication adherence: perceived treatment necessity, treatment concerns, satisfaction with care, treatment self-efficacy, coping, practical barriers, 
social support, disease or treatment understanding, illness beliefs/perceptions, and lifestyle. The necessity/concerns balance and practical barriers had the strongest association with medication adherence [10,53]. As stated in the introduction, behavioral intentions are driven by both explicit (conscious) and implicit (unconscious) attitudes [17]. Habitual behavior such as medication taking is guided stronger by implicit attitudes than by explicit attitudes, which play a stronger role in conscious (planned) behavior [19]. To understand the possible role of implicit attitudes regarding medication-taking behavior, we performed an explorative study with 52 patients who showed that explicit attitudes were positive and health-related. Implicit attitudes were, however, negative and illness-related. Half of the patients displayed explicitly positive but implicitly negative attitudes [30]. The relationship between implicit attitudes and medication adherence is worth being further explored to potentially make interventions more effective.

\section{Program Outcomes and Objectives}

The primary outcome of the intervention is to become adherent and maintain adherence to antirheumatic drugs, which was defined as taking at least $80 \%$ of the prescribed doses. This cutoff is widely used in (RA) adherence research and associated with improved in clinical outcomes in RA [5]. It is increasingly recognized that medication adherence is not an order from a clinician for the patient to execute ("compliance" to therapy) but requires active patient participation and stimulation (adherence). Thus, an intervention enhanced with positive affect is more successful in increasing adherence [58]. In addition, the explorative study learned that patients' implicit and explicit attitudes do not correlate and that implicit attitudes are generally negative and illness-related. Therefore, the expert group considered that reconditioning implicit negative attitudes to more positive ones could shift the necessity/concerns balance. In that light, the expert group drafted a change objective that was adjusted and refined over several rounds of discussion. Ultimately, this led to the following change objective: after the intervention, participants have a more positive attitude toward antirheumatic drugs.

\section{Program Design}

The explorative study in patients with RA performed in step 1 learned that, generally, explicit attitudes are positive and implicit attitudes are negative [30]. To enable change to occur, the expert group aimed at reducing negative explicit attitudes and reinforcing positive implicit attitudes (see Table 1). The idea was that the net result of these 2 actions would be overall a more positive attitude toward medication. Medication concerns can be targeted by patient education [12,51]. Thus, our strategy was to explicitly reduce concerns by educating patients on how to best use antirheumatic drugs. The literature search on bias modifications to change implicit attitudes led to multiple reviews with examples of gamified behavior change techniques [20,21]. To positively influence the associations between medication beliefs and medication use on an implicit level, 3 mental domains can be addressed: cognition (knowing), affect (feeling), and motivation (willing) [20].

Cognitions/beliefs can be altered using attentional bias modification training [21]. During training, attention is shifted in a positive direction by repetitively drawing attention to positive associations between medication beliefs and medication use. Similarly, affect can be modified by training participants to pair medication with another positive stimulus-so called evaluative conditioning. Lastly, motivation can be implicitly targeted by goal priming: passive and unobtrusive activation of people without them being aware of it. Taken together, we applied 1 explicit and 3 implicit strategies as underpinning for behavior change to occur. Implicit attitudes are activated automatically, but like old habits, are harder to change [17]. Thus, a multidose intervention in the form of a serious game was chosen. The expert group identified game types that fit the target population, which in the case of RA are mainly women over the age of 50 years. One of the favorite leisure time activities is solving puzzles, and therefore, it was decided to develop a serious puzzle game [59,60].

\section{Program Production}

The design of the game environment needed to merge medication and puzzles and simultaneously be positive and energizing. The game was named Medi and Seintje, which is a Dutch wordplay on medication and signaling. Medi and Seintje are icon characters that look like a tablet and capsule, respectively (see Figure 1A). To ensure that participants would relate to the game, game personification was built in. If participants allowed camera use, they could take a picture of themselves and of their medication, which was used in the behavior change techniques (see below). Next, the behavior change techniques had to be integrated into the puzzle game in such a way that participants would encounter them without being too obtrusive to disturb gameplay. The behavior change techniques were added to the puzzle environment as so called "triggers" that allowed participants to open the game or a puzzle. A total of 5 triggers were developed: multiple choice medication quiz, dot-probe task, visual search, slide to unlock (see Figure 1B), and a barcode scanner (see Multimedia Appendix 1). These triggers were gamified behavior change techniques and considered important game components (see Table 1). After completing the trigger at start-up, the game offered 4 puzzle types (see Figure 1C and Figure 1D), each with 3 levels of difficulty: crossword, sudoku, wordsearch, and tangram. The game environment adhered to the Medi and Seintje theme. The first 4 steps of intervention mapping have been summarized in Table 2 and Table 3. 
Figure 1. Screenshots of the serious puzzle games. A. Icon characters Medi and Seintje introduce themselves. B. Users are instructed to slide the pill down the screen toward a picture of the user to unlock trigger. C. The puzzle menu showing the 4 puzzle types: crossword, sudoku, word search, and tangram. D. Example of the crossword puzzle screen.

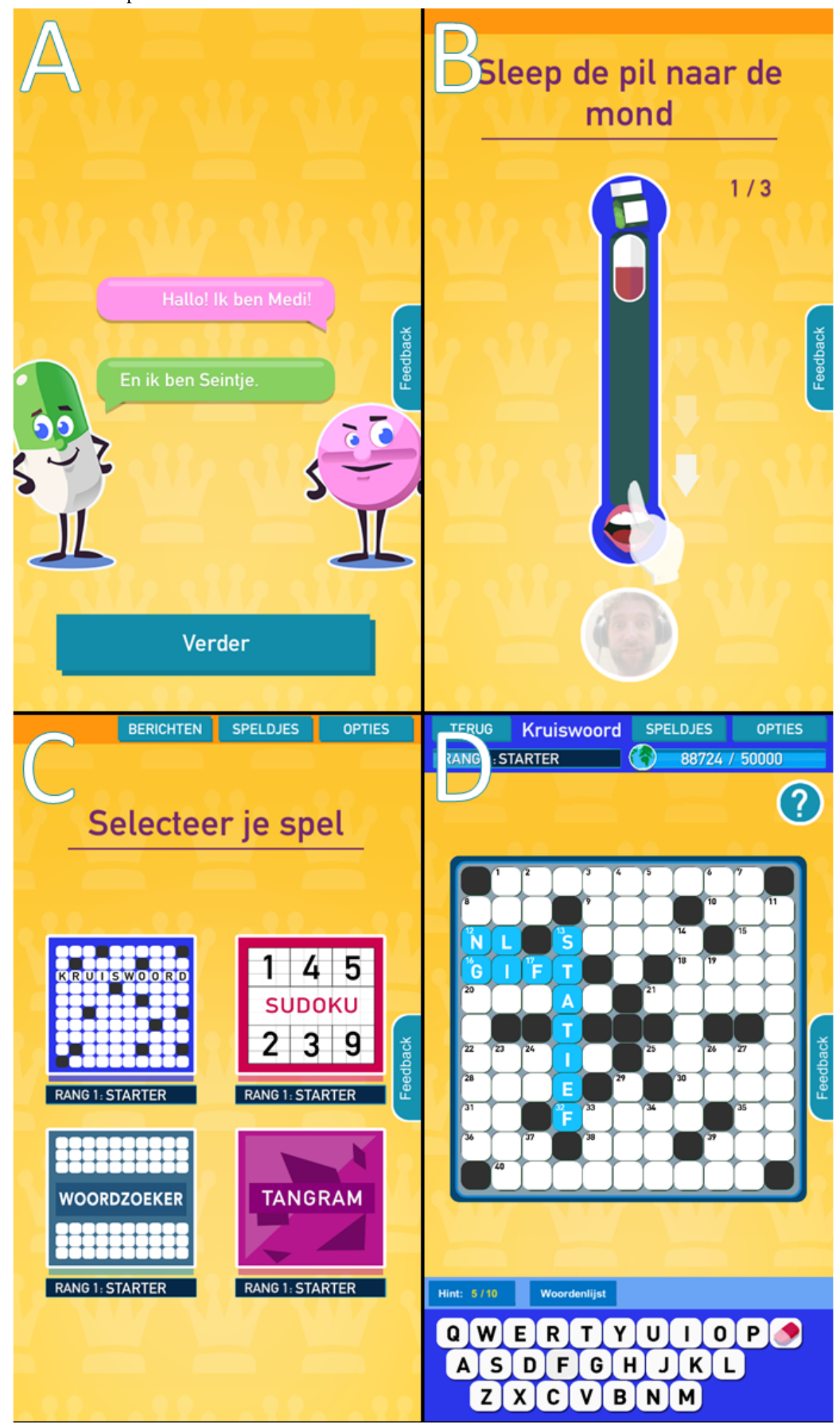


Table 2. From change objective to intervention strategies-the first 2 steps of intervention mapping.

\begin{tabular}{lll}
\hline Step & Goal & Outcome \\
\hline Step 1 & Determinants & $\bullet$ Treatment necessity \\
& & Treatment concerns
\end{tabular}

Step 2

Change objective

After the intervention, participants have a more positive attitude toward antirheumatic drugs.

Table 3. From change objective to intervention strategies — step 3 and step 4 of intervention mapping.

\begin{tabular}{|c|c|c|c|c|}
\hline \multirow[t]{2}{*}{ Step, goal } & \multicolumn{4}{|l|}{ Strategies and outcomes } \\
\hline & 1 & 2 & 3 & 4 \\
\hline \multicolumn{5}{|l|}{ Step 3} \\
\hline Domain & Motivation-implicit & Affective-implicit & Cognitive-implicit & Cognitive-explicit \\
\hline Strategy & $\begin{array}{l}\text { Goal priming: passive, subtle, } \\
\text { and unobtrusive activation by } \\
\text { external stimuli such that peo- } \\
\text { ple are not aware of the influ- } \\
\text { ence exerted by those stimuli. }\end{array}$ & $\begin{array}{l}\text { Reinforcing the positive va- } \\
\text { lence of antirheumatic drug } \\
\text { use by strengthening the posi- } \\
\text { tive associations through } \\
\text { pairing antirheumatic drugs } \\
\text { with a positive stimulus. }\end{array}$ & $\begin{array}{l}\text { Reinforcing attention toward } \\
\text { medication using positive } \\
\text { stimuli. Part of the tech- } \\
\text { niques applied are based on } \\
\text { attention bias modification } \\
\text { training. }\end{array}$ & $\begin{array}{l}\text { Reduce concerns by edu- } \\
\text { cating patients on how to } \\
\text { best use } \\
\text { antirheumatic drugs. }\end{array}$ \\
\hline \multicolumn{5}{|l|}{ Step 4} \\
\hline Game component & $\begin{array}{l}\text { Personalization of the } \\
\text { game } \\
\text { - Icon characters "Medi and } \\
\text { Seintje" } \\
\text { - Come-and-play reminder } \\
\text { - } \quad \text { Barcode scanner }\end{array}$ & 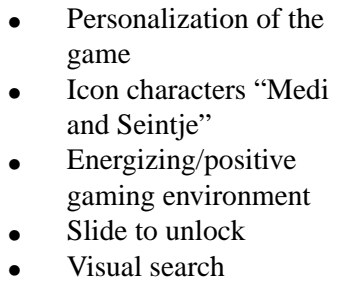 & $\begin{array}{l}\text { - Personalization of the } \\
\text { game } \\
\text { - } \quad \text { Icon characters "Medi } \\
\text { and Seintje" } \\
\text { - } \quad \text { Dot-probe task } \\
\text { - Visual search }\end{array}$ & $\begin{array}{ll}\text { - } & \text { Multiple choice } \\
\text { - } & \text { medication quiz }\end{array}$ \\
\hline
\end{tabular}

Out of 500 invitations, 54 DMARD users (11\%) agreed to test the game at stage 1 . Their median age was 63 years and the median number of years since diagnosis was 10 years. Thirty-three participants were female $(61 \%)$ and $39(72 \%)$ used their tablet daily. Stage 1 consisted of 2 rounds, where the feedback of round 1 was incorporated in the game before testing in round 2. Of the 52 participants, 39 participants completed the study: 9 participants did not download the app (reason unknown), 2 stopped owing to technical issues, and 2 stopped because of medical reasons. In round 1, 19 participants used the app and 22 participants used the app in round 2, of which 12 used the app in both rounds. On average, in round 1, users played 1.4 sessions per day that lasted 12 minutes, and in round 2, users played 1.7 sessions per day that lasted 16 minutes. Although playtime increased, there were no significant differences in the scores for ease of use, perceived usefulness, and attitude toward using between the 2 rounds. User experiences indicated a broad spectrum of views from joy from playing to annoyance. Suggestions for improvements given by participants were mainly about the barcode scanner, as the scanner malfunctioned in round 1. Other technical improvements that were suggested were a lower frequency of push notifications, larger display buttons, and preventing puzzles from causing the app to crash. Prior to the live walk-through in stage 2, the app received a major update to incorporate further improvements, such as instruction screens for all puzzles. During stage 2, eight DMARD users performed a walk-through under supervision at Sint Maartenskliniek. Four participants participated in stage 1, and 4 were new to the app. When seeing how users performed the various tasks, the app builders learned which steps were intuitive and which steps needed improvement. Overall, the design process led to valuable insights in patient acceptance, usability, and suggestions for improvement. Consequently, the latest version of the app complied with the needs of end users.

\section{Program Implementation Plan}

Implementation was ensured by evoking the intrinsic motivation of participants through addressing the following 3 needs: competence, autonomy, and relatedness [24,25,48]. The complete puzzle environment consisted of 3 puzzle types-crossword, sudoku, and wordsearch-with 3 levels of difficulty and at least 50 puzzles at each of these levels and 82 tangram puzzles across 4 themes: animals, letters, objects, and humans. To meet the need for competence, puzzles with increasing difficulty were available. Players could board a puzzle on the difficulty level they could master and develop skills by playing numerous puzzles in increasing difficulty. For players new to the game, there was an option to receive hints or help. The mastery of an individual was tracked by gaining experience points when playing puzzles, and they could view their progression level. Additionally, players could complete challenges such as "find a word within 5 seconds" after starting wordsearch to be rewarded with badges allowing them to track and visualize their progress. 
To meet the needs of autonomy, players had the freedom to choose which puzzle to play (individual choices were reflected in the badges collected) and the opportunity to solve a puzzle in multiple ways. Finally, to meet the need of relatedness, the world record playing crossword puzzles was incorporated in the game. By playing crossword puzzles, each player contributed to breaking the world record crossword puzzles, which was a group effort. Prior to starting a new crossword puzzle, the individual's contribution to the world record and total progress was shown. To protect the privacy of the individual participants, it was decided not to incorporate social interaction elements at this stage. To further prevent dropout, we sought to balance triggers versus puzzles. Balance turned out to be one trigger when starting the game and when opening a new puzzle after at least 10 minutes of solving puzzles. Triggers appeared in random order to maintain variety in gameplay.

\section{Evaluation Plan}

The intervention is currently being evaluated in a multicenter randomized clinical trial: the GAMER study [61]. This study aims to examine the effect on medication adherence and clinical outcomes in patients with RA treated with antirheumatic drugs. A total of 220 patients will be randomized 1:1 to intervention or usual care and followed for 3 months. The intervention group will be instructed to install and play the puzzle game on their tablet or mobile phone. Playing the puzzle game is encouraged at the start of the study but otherwise completely voluntary. The main study parameter is adherence using the validated CQR in an intention-to-treat analysis. Additionally, a pill count will be performed and the BMQ will be collected. Secondary clinical outcomes are the Health Assessment Questionnaire (HAQ) and the self-reported Rheumatoid Arthritis Disease Activity Index (RADAI). The CQR, BMQ, HAQ, and RADAI have been proven valid and reliable in patients with RA [32-38,62-66]. Disease activity $[67,68]$ will be gathered if available. Lastly, the Technology Acceptance Model, a well-established model for evaluating usability of eHealth, will be applied to collect patient acceptance of the puzzle game. Data collection will be similar to stage 1 of the user testing: the System Usability Scale will assess ease of use, GameFlow will assess perceived usefulness, part of the uMARS will assess the attitude toward using, and Google Analytics will collect actual use [39-46].

\section{Discussion}

This paper describes the design rationale of a serious game aimed at improving medication adherence in patients with RA. Our formative work with patients with RA in combination with the literature search and explorative study described above led us to develop a mobile serious game as an intervention. Focal points of this serious game were implicit medication attitudes, positivism, and retention.

As Abraham et al [69] stated, development of serious games should detail on the extent of the theoretical framework incorporated into the game design and evaluate success by testing the player's retention of learning objectives. This is why we chose to develop our intervention according to the intervention mapping framework while being guided by the Dual-Attitude Model and self-determination theory [17,24].
Even though the development was guided by the systematic intervention mapping framework, several choices still had to be made by the expert group. To ensure deliberate decisions, we sought to incorporate many different areas of expertise among group members from clinical to psychological and technical. Patients were not represented in the expert group but extensively consulted throughout the intervention mapping process: from the explorative study to elaborate user testing. The developed intervention did not contain medication-taking (reminder) components in contrast to other serious games aimed at improving medication adherence [69]. We decided not to incorporate the actual medication-taking behavior because we feared that this would be perceived as coercive and would lead to loss of retention because the act of medication taking would take playfulness and positivity out of the game.

The behavior change techniques we have applied as medication-related triggers have not previously been tested to improve medication adherence. Even though there is no solid evidence for improving medication adherence, the extensive research on these techniques for stimulating healthy behavior was considered a strong enough premise to apply these techniques in our serious gaming intervention [21]. Another reason for applying these behavior change techniques was the fact that they have been successfully and effectively gamified $[26,27]$. It should be noted that the test conditions for these behavior change techniques were generally well-controlled: playing the gamified behavior change techniques for a set period of time (at least for several minutes) without distractions. When applying these techniques in a mobile app as medication-related triggers, there is no control over the participants' setting, which leads to variable exposure to the triggers. To ensure that the triggers were sufficiently dosed, participants need to be intrinsically motivated to play the game. When developing a serious game, a trade-off has to be made between the serious (ie, the behavior change techniques) and the game (ie, the puzzles), which is why the usability testing is so important. The results from our usability testing indicated a positive response toward the app. However, these findings were prone to selection bias and limited to patients willing to test the app. This type of testing, while appropriate for app development, may not reveal barriers to implementation in practice. The app was carefully designed to quickly engage users, sustain motivation for long-term app use, and simultaneously apply behavior change techniques. The success of these strategies will not be known until the app is tested in clinical practice. To be considered effective, serious games must sustain their impact over the long term and offer more than a short-term novelty effect [69]. The results of our evaluation study will hopefully answer if our serious game is successful in improving medication adherence [61]. If proven effective, additional studies should be performed to assess effectiveness in the longer term (6-12 months) and to investigate the effective components more closely.

In conclusion, we systematically developed a serious game app to enhance adherence to antirheumatic drugs among patients with RA by using the intervention mapping framework. Evaluation in a multicenter randomized controlled trial will determine intervention uptake and effectiveness. This paper 
could serve as a guideline for other health care providers when developing similar interventions.

\section{Acknowledgments}

We would like to thank Games for Health for developing the game in cocreation with the expert group. Specials thanks to Rob Tieben from Games for Health for critically reviewing the manuscript.

\section{Conflicts of Interest}

None declared.

\section{Multimedia Appendix 1}

Triggers of serious game Medi and Seintje explained.

[DOCX File, 413 KB-Multimedia Appendix 1]

\section{References}

1. van der Woude D, van der Helm-van Mil AHM. Update on the epidemiology, risk factors, and disease outcomes of rheumatoid arthritis. Best Pract Res Clin Rheumatol 2018 Apr;32(2):174-187. [doi: 10.1016/j.berh.2018.10.005] [Medline: 30527425]

2. Aletaha D, Smolen JS. Diagnosis and Management of Rheumatoid Arthritis: A Review. JAMA 2018 Oct 02;320(13):1360-1372. [doi: 10.1001/jama.2018.13103] [Medline: 30285183]

3. Smolen JS, Landewé RBM, Bijlsma JWJ, Burmester GR, Dougados M, Kerschbaumer A, et al. EULAR recommendations for the management of rheumatoid arthritis with synthetic and biological disease-modifying antirheumatic drugs: 2019 update. Ann Rheum Dis 2020 Jun;79(6):685-699. [doi: 10.1136/annrheumdis-2019-216655] [Medline: 31969328]

4. Pasma A, Schenk CV, Timman R, Busschbach JJV, van den Bemt BJF, Molenaar E, et al. Non-adherence to disease-modifying antirheumatic drugs is associated with higher disease activity in early arthritis patients in the first year of the disease. Arthritis Res Ther 2015 Oct 08;17:281 [FREE Full text] [doi: 10.1186/s13075-015-0801-4] [Medline: 26449852]

5. Waimann CA, Marengo MF, de Achaval S, Cox VL, Garcia-Gonzalez A, Reveille JD, et al. Electronic monitoring of oral therapies in ethnically diverse and economically disadvantaged patients with rheumatoid arthritis: consequences of low adherence. Arthritis Rheum 2013 Jun;65(6):1421-1429 [FREE Full text] [doi: 10.1002/art.37917] [Medline: 23728826]

6. Wabe N, Lee A, Wechalekar M, McWilliams L, Proudman S, Wiese M. Adherence to combination DMARD therapy and treatment outcomes in rheumatoid arthritis: a longitudinal study of new and existing DMARD users. Rheumatol Int 2017 Jun;37(6):897-904. [doi: 10.1007/s00296-017-3655-z] [Medline: 28160071]

7. van den Bemt BJF, Zwikker HE, van den Ende CHM. Medication adherence in patients with rheumatoid arthritis: a critical appraisal of the existing literature. Expert Rev Clin Immunol 2012 May;8(4):337-351. [doi: 10.1586/eci.12.23] [Medline: 22607180]

8. Murage M, Tongbram V, Feldman S, Malatestinic W, Larmore C, Muram T, et al. Medication adherence and persistence in patients with rheumatoid arthritis, psoriasis, and psoriatic arthritis: a systematic literature review. PPA 2018 Aug;Volume 12:1483-1503. [doi: 10.2147/ppa.s167508]

9. Scheiman-Elazary A, Duan L, Shourt C, Agrawal H, Ellashof D, Cameron-Hay M, et al. The Rate of Adherence to Antiarthritis Medications and Associated Factors among Patients with Rheumatoid Arthritis: A Systematic Literature Review and Metaanalysis. J Rheumatol 2016 Mar;43(3):512-523. [doi: 10.3899/jrheum.141371] [Medline: 26879354]

10. Horne R, Chapman SCE, Parham R, Freemantle N, Forbes A, Cooper V. Understanding patients' adherence-related beliefs about medicines prescribed for long-term conditions: a meta-analytic review of the Necessity-Concerns Framework. PLoS One 2013;8(12):e80633 [FREE Full text] [doi: 10.1371/journal.pone.0080633] [Medline: 24312488]

11. Vangeli E, Bakhshi S, Baker A, Fisher A, Bucknor D, Mrowietz U, et al. A Systematic Review of Factors Associated with Non-Adherence to Treatment for Immune-Mediated Inflammatory Diseases. Adv Ther 2015 Nov;32(11):983-1028 [FREE Full text] [doi: 10.1007/s12325-015-0256-7] [Medline: 26547912]

12. Rashid MA, Llanwarne N, Heyns N, Walter F, Mant J. What are the implications for practice that arise from studies of medication taking? A systematic review of qualitative research. PLoS One 2018;13(5):e0195076 [FREE Full text] [doi: 10.1371/journal.pone.0195076] [Medline: 29768417]

13. Conn VS, Ruppar TM. Medication adherence outcomes of 771 intervention trials: Systematic review and meta-analysis. Prev Med 2017 Jun;99:269-276 [FREE Full text] [doi: 10.1016/j.ypmed.2017.03.008] [Medline: 28315760]

14. Wilhelmsen NC, Eriksson T. Medication adherence interventions and outcomes: an overview of systematic reviews. Eur J Hosp Pharm 2019 Jul;26(4):187-192 [FREE Full text] [doi: 10.1136/ejhpharm-2018-001725] [Medline: $\underline{31338165]}$

15. Kini V, Ho PM. Interventions to Improve Medication Adherence: A Review. JAMA 2018 Dec 18;320(23):2461-2473. [doi: 10.1001/jama.2018.19271] [Medline: $\underline{\text { 30561486] }}$ 
16. Nieuwlaat R, Wilczynski N, Navarro T, Hobson N, Jeffery R, Keepanasseril A, et al. Interventions for enhancing medication adherence. Cochrane Database Syst Rev 2014 Nov 20(11):CD000011 [FREE Full text] [doi: 10.1002/14651858.CD000011.pub4] [Medline: 25412402]

17. Wilson TD, Lindsey S, Schooler TY. A model of dual attitudes. Psychol Rev 2000 Jan;107(1):101-126. [doi: 10.1037/0033-295x.107.1.101] [Medline: 10687404]

18. St Quinton T, Brunton JA. Implicit Processes, Self-Regulation, and Interventions for Behavior Change. Front Psychol 2017;8:346 [FREE Full text] [doi: 10.3389/fpsyg.2017.00346] [Medline: 28337164]

19. Friese M, Wänke M, Plessner H. Implicit consumer preferences and their influence on product choice. Psychol. Mark 2006 Sep;23(9):727-740. [doi: 10.1002/mar.20126]

20. Sheeran P, Gollwitzer PM, Bargh JA. Nonconscious processes and health. Health Psychol 2013 May;32(5):460-473. [doi: 10.1037/a0029203] [Medline: 22888816]

21. Jones EB, Sharpe L. Cognitive bias modification: A review of meta-analyses. J Affect Disord 2017 Dec 01;223:175-183. [doi: 10.1016/j.jad.2017.07.034] [Medline: 28759865]

22. Dörner R, Göbel S, Effelsberg W, Wiemeyer J. What are serious games? In: Serious Games Foundations, Concepts and Practice. Switzerland: Springer International Publishing; 2016:2-4.

23. Kato PM. Video Games in Health Care: Closing the Gap. Review of General Psychology 2010 Jun 01;14(2):113-121. [doi: $\underline{10.1037 / a 0019441]}$

24. Ryan RM, Deci EL. Self-determination theory and the facilitation of intrinsic motivation, social development, and well-being. Am Psychol 2000 Jan;55(1):68-78. [doi: 10.1037//0003-066x.55.1.68] [Medline: 11392867]

25. Ryan R, Deci E. Self-determination theory. Center for Self-Determination Theory. 2021. URL: https://selfdeterminationtheory. org/ [accessed 2022-01-31]

26. DeSmet A, Van Ryckeghem D, Compernolle S, Baranowski T, Thompson D, Crombez G, et al. A meta-analysis of serious digital games for healthy lifestyle promotion. Prev Med 2014 Dec;69:95-107 [FREE Full text] [doi:

10.1016/j.ypmed.2014.08.026] [Medline: 25172024]

27. Alblas EE, Folkvord F, Anschütz DJ, Van 't Riet J, Ketelaar P, Buijzen M. A Health Game Targeting Children's Implicit Attitudes and Snack Choices. Games Health J 2020 Dec;9(6):425-435. [doi: 10.1089/g4h.2019.0103] [Medline: 32735454]

28. Kok G, Gottlieb NH, Peters GY, Mullen PD, Parcel GS, Ruiter RA, et al. A taxonomy of behaviour change methods: an Intervention Mapping approach. Health Psychol Rev 2016 Sep;10(3):297-312 [FREE Full text] [doi:

10.1080/17437199.2015.1077155] [Medline: 26262912]

29. Peters G. Intervention Mapping. URL: https://interventionmapping.com/ [accessed 2022-01-31]

30. Linn AJ, Vandeberg L, Wennekers AM, Vervloet M, van Dijk L, van den Bemt BJF. Disentangling Rheumatoid Arthritis Patients' Implicit and Explicit Attitudes toward Methotrexate. Front Pharmacol 2016;7:233 [FREE Full text] [doi: 10.3389/fphar.2016.00233] [Medline: 27559311]

31. Karpinski A, Steinman RB. The single category implicit association test as a measure of implicit social cognition. J Pers Soc Psychol 2006 Jul;91(1):16-32. [doi: 10.1037/0022-3514.91.1.16] [Medline: 16834477]

32. Horne R, Weinman J, Hankins M. The beliefs about medicines questionnaire: The development and evaluation of a new method for assessing the cognitive representation of medication. Psychology \& Health 1999 Jan;14(1):1-24. [doi: 10.1080/08870449908407311]

33. Clifford S, Barber N, Horne R. Understanding different beliefs held by adherers, unintentional nonadherers, and intentional nonadherers: application of the Necessity-Concerns Framework. J Psychosom Res 2008 Jan;64(1):41-46. [doi: 10.1016/j.jpsychores.2007.05.004] [Medline: 18157998]

34. McCulley C, Katz P, Trupin L, Yelin EH, Barton JL. Association of Medication Beliefs, Self-efficacy, and Adherence in a Diverse Cohort of Adults with Rheumatoid Arthritis. J Rheumatol 2018 Dec;45(12):1636-1642 [FREE Full text] [doi: 10.3899/jrheum.171339] [Medline: 30219761]

35. Michaud K, Vrijens B, Tousset E, Pedro S, Schumacher R, Dasic G, et al. Real-World Adherence to Oral Methotrexate Measured Electronically in Patients With Established Rheumatoid Arthritis. ACR Open Rheumatol 2019 Nov;1(9):560-570 [FREE Full text] [doi: 10.1002/acr2.11079] [Medline: $\underline{\text { 31777840] }}$

36. de Klerk E, van der Heijde D, Landewé R, van der Tempel H, van der Linden S. The compliance-questionnaire-rheumatology compared with electronic medication event monitoring: a validation study. J Rheumatol 2003 Nov;30(11):2469-2475. [Medline: 14677194]

37. de Klerk E, van der Heijde D, van der Tempel H, van der Linden S. Development of a questionnaire to investigate patient compliance with antirheumatic drug therapy. J Rheumatol 1999 Dec;26(12):2635-2641. [Medline: 10606375]

38. Salt E, Hall L, Peden AR, Home R. Psychometric properties of three medication adherence scales in patients with rheumatoid arthritis. J Nurs Meas 2012;20(1):59-72. [doi: 10.1891/1061-3749.20.1.59] [Medline: 22679710]

39. Davis F. A technology acceptance model for empirically testing new end-user information systems: theory and results. Massachusetts Institute of Technology. 1985. URL: https://dspace.mit.edu/handle/1721.1/15192 [accessed 2022-02-01]

40. Harst L, Lantzsch H, Scheibe M. Theories Predicting End-User Acceptance of Telemedicine Use: Systematic Review. J Med Internet Res 2019 May 21;21(5):e13117 [FREE Full text] [doi: 10.2196/13117] [Medline: 31115340] 
41. Bonten TN, Rauwerdink A, Wyatt JC, Kasteleyn MJ, Witkamp L, Riper H, EHealth Evaluation Research Group. Online Guide for Electronic Health Evaluation Approaches: Systematic Scoping Review and Concept Mapping Study. J Med Internet Res 2020 Aug 12;22(8):e17774 [FREE Full text] [doi: 10.2196/17774] [Medline: 32784173]

42. Brooke J. SUS: A quick and dirty usability scale. In: Usability Evaluation In Industry. London: CRC Press; 2014.

43. Bangor A, Kortum P, Miller J. Determining what individual SUS scores mean: adding an adjective rating scale. Journal of Usability Studies. 2009 May. URL: https://uxpajournal.org/ determining-what-individual-sus-scores-mean-adding-an-adjective-rating-scale/ [accessed 2022-02-01]

44. Sweetser P, Wyeth P. GameFlow. Comput. Entertain 2005 Jul;3(3):3-3. [doi: 10.1145/1077246.1077253]

45. Sweetser P, Johnson D, Wyeth P, Anwar A, Meng Y, Ozdowska A. GameFlow in Different Game Genres and Platforms. Comput. Entertain 2017 Apr 05;15(3):1-24. [doi: 10.1145/3034780]

46. Stoyanov SR, Hides L, Kavanagh DJ, Wilson H. Development and Validation of the User Version of the Mobile Application Rating Scale (uMARS). JMIR Mhealth Uhealth 2016 Jun 10;4(2):e72 [FREE Full text] [doi: 10.2196/mhealth.5849] [Medline: 27287964]

47. Terhorst Y, Philippi P, Sander LB, Schultchen D, Paganini S, Bardus M, et al. Validation of the Mobile Application Rating Scale (MARS). PLoS One 2020;15(11):e0241480 [FREE Full text] [doi: 10.1371/journal.pone.0241480] [Medline: 33137123]

48. Przybylski AK, Rigby CS, Ryan RM. A Motivational Model of Video Game Engagement. Review of General Psychology 2010 Jun 01;14(2):154-166. [doi: 10.1037/a0019440]

49. van Mierlo T, Fournier R, Ingham M. Targeting Medication Non-Adherence Behavior in Selected Autoimmune Diseases: A Systematic Approach to Digital Health Program Development. PLoS One 2015;10(6):e0129364 [FREE Full text] [doi: 10.1371/journal.pone.0129364] [Medline: 26107637]

50. Voshaar MJH, Nota I, van de Laar MAFJ, van den Bemt BJF. Patient-centred care in established rheumatoid arthritis. Best Pract Res Clin Rheumatol 2015;29(4-5):643-663. [doi: 10.1016/j.berh.2015.09.007] [Medline: 26697772]

51. Joplin S, van der Zwan R, Joshua F, Wong PKK. Medication adherence in patients with rheumatoid arthritis: the effect of patient education, health literacy, and musculoskeletal ultrasound. Biomed Res Int 2015;2015:150658 [FREE Full text] [doi: 10.1155/2015/150658] [Medline: 26060812]

52. Kumar K, Raza K, Nightingale P, Horne R, Chapman S, Greenfield S, et al. Determinants of adherence to disease modifying anti-rheumatic drugs in White British and South Asian patients with rheumatoid arthritis: a cross sectional study. BMC Musculoskelet Disord 2015 Dec 29;16:396 [FREE Full text] [doi: 10.1186/s12891-015-0831-8] [Medline: 26714853]

53. Morgan C, McBeth J, Cordingley L, Watson K, Hyrich KL, Symmons DPM, et al. The influence of behavioural and psychological factors on medication adherence over time in rheumatoid arthritis patients: a study in the biologics era. Rheumatology (Oxford) 2015 Oct;54(10):1780-1791 [FREE Full text] [doi: 10.1093/rheumatology/kev105] [Medline: 25972390]

54. Pascual-Ramos V, Contreras-Yáñez I. Motivations for inadequate persistence with disease modifying anti-rheumatic drugs in early rheumatoid arthritis: the patient's perspective. BMC Musculoskelet Disord 2013 Dec 01;14:336 [FREE Full text] [doi: 10.1186/1471-2474-14-336] [Medline: 24289729]

55. Pasma A, van't Spijker A, Hazes JMW, Busschbach JJV, Luime JJ. Factors associated with adherence to pharmaceutical treatment for rheumatoid arthritis patients: a systematic review. Semin Arthritis Rheum 2013 Aug;43(1):18-28. [doi: 10.1016/j.semarthrit.2012.12.001] [Medline: 23352247]

56. Pasma A, van 't Spijker A, Luime JJ, Walter MJM, Busschbach JJV, Hazes JMW. Facilitators and barriers to adherence in the initiation phase of Disease-modifying Antirheumatic Drug (DMARD) use in patients with arthritis who recently started their first DMARD treatment. J Rheumatol 2015 Mar;42(3):379-385. [doi: 10.3899/jrheum.140693] [Medline: 25512473]

57. Salaffi F, Carotti M, Di Carlo M, Farah S, Gutierrez M. Adherence to Anti-Tumor Necrosis Factor Therapy Administered Subcutaneously and Associated Factors in Patients With Rheumatoid Arthritis. J Clin Rheumatol 2015 Dec;21(8):419-425. [doi: 10.1097/RHU.0000000000000320] [Medline: 26587852]

58. Ogedegbe GO, Boutin-Foster C, Wells MT, Allegrante JP, Isen AM, Jobe JB, et al. A randomized controlled trial of positive-affect intervention and medication adherence in hypertensive African Americans. Arch Intern Med 2012 Feb 27;172(4):322-326 [FREE Full text] [doi: 10.1001/archinternmed.2011.1307] [Medline: 22269592]

59. Rijksinstituut voor Volksgezondheid en Milieu, Centraal Bureau voor de Statistiek. Zitgedrag. Leefstijlmonitor. 2019. URL: https://www.sportenbewegenincijfers.n1/kernindicatoren/zitgedrag [accessed 2022-02-01]

60. Bureau of Labor Statistics. Leisure time on an average day. American Time Use Survey. 2015. URL: https://www.bls.gov/ TUS/CHARTS/LEISURE.HTM [accessed 2022-02-01]

61. Pouls BPH. Trial NL7217. Dutch Trial Register. URL: https://www.trialregister.nl/trial/7217 [accessed 2022-01-31]

62. Fries JF, Spitz P, Kraines RG, Holman HR. Measurement of patient outcome in arthritis. Arthritis Rheum 1980 Feb;23(2):137-145. [doi: 10.1002/art.1780230202] [Medline: 7362664]

63. Boers M, Jacobs JWG, van Vliet Vlieland TPM, van Riel PLCM. Consensus Dutch health assessment questionnaire. Ann Rheum Dis 2007 Jan;66(1):132-133 [FREE Full text] [doi: 10.1136/ard.2006.059451] [Medline: 17178759]

64. Fransen J, Langenegger T, Michel BA, Stucki G. Feasibility and validity of the RADAI, a self-administered rheumatoid arthritis disease activity index. Rheumatology (Oxford) 2000 Mar;39(3):321-327. [doi: 10.1093/rheumatology/39.3.321] [Medline: 10788543] 
65. Fransen J, Häuselmann H, Michel BA, Caravatti M, Stucki G. Responsiveness of the self-assessed rheumatoid arthritis disease activity index to a flare of disease activity. Arthritis Rheum 2001 Jan;44(1):53-60 [FREE Full text] [doi: 10.1002/1529-0131(200101)44:1<53::AID-ANR8>3.0.CO;2-O] [Medline: 11212176 ]

66. AlOmeir O, Patel N, Donyai P. Adherence to adjuvant endocrine therapy among breast cancer survivors: a systematic review and meta-synthesis of the qualitative literature using grounded theory. Support Care Cancer 2020

Nov;28(11):5075-5084 [FREE Full text] [doi: 10.1007/s00520-020-05585-9] [Medline: 32601852]

67. Prevoo ML, van 't Hof MA, Kuper HH, van Leeuwen MA, van de Putte LB, van Riel PL. Modified disease activity scores that include twenty-eight-joint counts. Development and validation in a prospective longitudinal study of patients with rheumatoid arthritis. Arthritis Rheum 1995 Jan;38(1):44-48. [doi: 10.1002/art.1780380107] [Medline: 7818570]

68. van Riel PLCM, Renskers L. The Disease Activity Score (DAS) and the Disease Activity Score using 28 joint counts (DAS28) in the management of rheumatoid arthritis. Clin Exp Rheumatol 2016;34(5 Suppl 101):S40-S44 [FREE Full text] [Medline: 27762189]

69. Abraham O, LeMay S, Bittner S, Thakur T, Stafford H, Brown R. Investigating Serious Games That Incorporate Medication Use for Patients: Systematic Literature Review. JMIR Serious Games 2020 Apr 29;8(2):e16096 [FREE Full text] [doi: 10.2196/16096] [Medline: $\underline{32347811]}$

\author{
Abbreviations \\ BMQ: Beliefs about Medication Questionnaire \\ CQR: Compliance Questionnaire on Rheumatology \\ DMARD: disease-modifying antirheumatic drugs \\ GAMER: Gaming for Adherence to Medication using E-health in Rheumatoid arthritis patients \\ HAQ: Health Assessment Questionnaire \\ RA: rheumatoid arthritis \\ RADAI: Rheumatoid Arthritis Disease Activity Index \\ UMARS: user version of the Mobile App Rating Scale
}

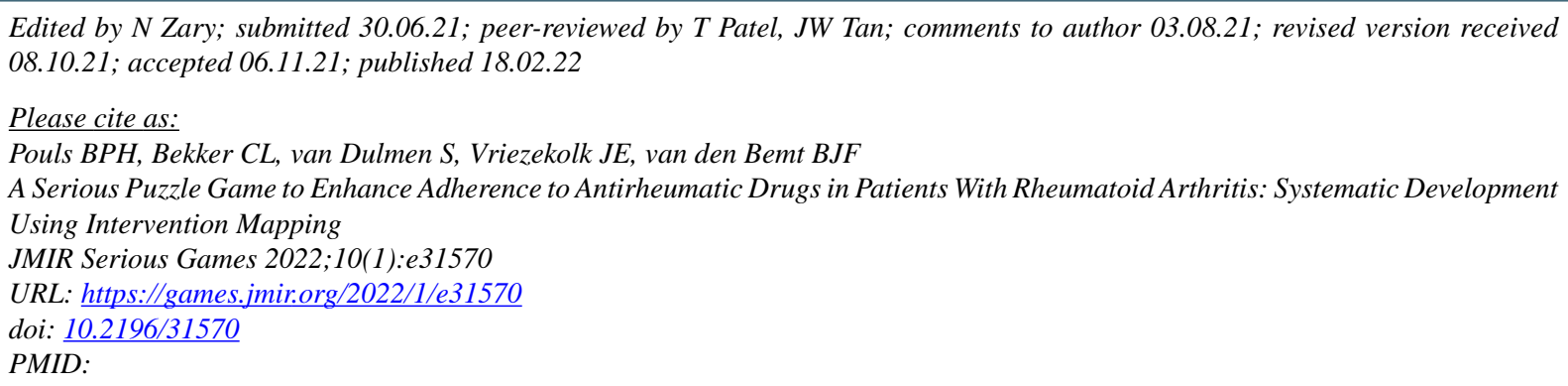

CBart PH Pouls, Charlotte L Bekker, Sandra van Dulmen, Johanna E Vriezekolk, Bart JF van den Bemt. Originally published in JMIR Serious Games (https://games.jmir.org), 18.02.2022. This is an open-access article distributed under the terms of the Creative Commons Attribution License (https://creativecommons.org/licenses/by/4.0/), which permits unrestricted use, distribution, and reproduction in any medium, provided the original work, first published in JMIR Serious Games, is properly cited. The complete bibliographic information, a link to the original publication on https://games.jmir.org, as well as this copyright and license information must be included. 